Orbis Tertius, vol. XXII, n 26 , e059, diciembre 2017. ISSN 1851-7811

Universidad Nacional de La Plata

Facultad de Humanidades y Ciencias de la Educación

Centro de Estudios de Teoría y Crítica Literaria

\title{
Otras voces y otros ámbitos para la Historia de la Lectura
}

\author{
Alejandro E. Parada * \\ * Universidad de Buenos Aires, Argentina
}

\section{Uno}

La pregunta por el origen de una disciplina se relaciona con sus propias esencias. Constituye un interrogante respecto de dónde procede un ente o una cosa y mediante qué medio es como es y, en definitiva, qué es (Heidegger 2003). Reflexionar sobre los orígenes de una disciplina impone una carga ontológica y su referencia existencial entre lo corpóreo y lo inmaterial. ¿Cuál es, entonces, la esencia que precipita y hace a la Historia de Lectura? Es decir, aquella última cosa sin la cual no existiría su estudio.

La respuesta es significativa: los lectores son los que justifican la Historia de la Lectura. Lo nominativo de esta materia, lo que le brinda su identidad e impone su quehacer, la pauta que despliega el nombre para que instrumentemos su propia especificidad, inequívocamente, son los lectores y no, en particular, otra cosa. Lo que “cosifica” en forma unívoca e identitaria a este relato de la historia y, sin duda, lo reviste de novedad, se afinca en la residencia de los lectores. El acto de leer y su narrativa a lo largo del tiempo, con sus variaciones de usos y modalidades, con sus cambios y pasiones emocionales, con sus instancias de mutaciones de soportes, tienen como resultado final el enigma y la encrucijada del lector.

¿Pero qué hacemos cuando en la actualidad hacemos Historia de la Lectura? La Historia de la Lectura moderna tiende a desacralizar la participación del autor y a entronizar la actividad de los que leen (Chartier 1993; Foucault 1999). La complejidad de esa tensa y ubérrima relación entre los autores y los lectores es lo que caracteriza a esta disciplina en construcción. En este juego de tensiones no se debe olvidar la tonalidad que se construye con la dialéctica autor-lector.

Acaso sea necesario rescatar la faceta autoral para llevarla con nuevo brío a su enfrentamiento con el lector. La Historia de la Lectura es la narración de esta pugna creadora entre quienes escriben y quienes leen. La doble morfología de este vínculo con lo verosímil enriquecerá a los lectores. Solapar u ocultar a los autores con la retórica exclusiva del lector, es una forma de pauperizar el universo de la lectura.

No obstante, es necesario reparar en otros aspectos. Y esos elementos se entrelazan, en los orígenes de la Historia de la Lectura, con la necesidad de definir sus características. ¿Cuáles son, pues, esas propiedades de identificación? Porque estamos ante una disciplina que no se agota en una retórica dialéctica entre los lectores y

Cita sugerida: Parada, A. E. (2017). Otras voces y otros ámbitos para la Historia de la Lectura. Orbis Tertius, $22(26)$, e059. https://doi.org/10.24215/18517811e059 
los autores. Lo que individualiza su modus operandi, casi exclusivamente, son los estudios de caso y, en particular, la subjetividad de su objeto de estudio.

Los historiadores de la lectura suelen enfrentarse ante un obstáculo de compleja resolución. Los testimonios que cuentan para reconstruir el universo lector son, por definición, heterogéneos. Deben recurrir y, a veces, abusivamente, al método interpretativo para historiar cómo se leía y por qué se leía, para luego intentar recrear históricamente los cambios que obraron los textos en las personas.

La Historia de la Lectura actualmente posee una fuerte dosis de relatividad al abordar sus objetos de estudio. La fragmentación de los modos de acceder a las lecturas del pasado ha provocado un exceso de los procesos indiciarios y, en consecuencia, un aumento de las aproximaciones relativas. El relativismo, a su vez, establece un círculo vicioso entre la génesis de la documentación y su valor.

Esta problemática instala una nueva interrogante: ¿con qué fuentes es posible rastrear el universo de los lectores? El abordaje de las fuentes documentales no es un tema menor, ya que la Historia de la Lectura se puede narrar con un conjunto de testimonios que la historia tradicional no tenía en cuenta (Darnton 1993; Ginzburg 1999, 2008 y 2010). Sin embargo, no todas las fuentes alcanzan la categoría de documentos. La Historia de la Lectura, en este contexto, para no caer en la dispersión relativista de sus objetos de análisis, debe preguntarse sobre una cuestión fundamental: ¿qué es para ella un documento? (Buckland 1997). Se requiere, pues, de una sistematización documentaria, más o menos definida, adonde puedan recurrir, de común acuerdo, los historiadores de la lectura.

Pero la Historia Cultural no suele tener hechos sino símbolos (Geertz 1990) y representaciones culturales que se basan en ciertos hechos. ¿Cuál es entonces el umbral, en la Historia de la Lectura, entre esos hechos y las "huellas indiciarias” (Ginzburg 2004; 2008) o interpretativas? La metodología documentaria establece el rumbo y el carácter fragmentario de esta disciplina. Su diseminación y su énfasis polifónico se articulan con esta situación epocal de culto a los "fragmentos de la modernidad" (Frisby 1992) y, por ende, de acceder a las lecturas del pasado bajo la tutela de la dispersión.

Por otra parte, el fenómeno multidisciplinar determina y condiciona la masa testimonial con la que se nutre la Historia de la Lectura. Porque esta asignatura no es materia cuya puesta en texto sea solo una exclusividad de los historiadores. Además de estos últimos, quienes abordan sus disímiles temáticas provienen de distintas áreas: sociólogos, críticos literarios, editores, psicólogos, antropólogos, especialistas en edición, bibliotecarios, historiadores del arte, libreros, etcétera. De este modo, la Historia de la Lectura es una especie de textualidad comunitaria o cooperativa de las disciplinas que conforman las Humanidades y las Ciencias Sociales. Cada esfera, inequívocamente, instrumenta sus procederes a partir de sus propios documentos. Para comprender las variaciones temáticas y la atomización de las historias de los lectores, es necesario rastrear el enfoque que motivó cada relato histórico.

Estas características que hemos enumerado -multiplicación y subjetividad del objeto de estudio, dispersión y fragmentación en los enfoques, variaciones y aproximaciones aleatorias a los documentos, y la relectura constante de parte de una escritura proveniente de las Ciencias Sociales- son elementos singulares en la Historia de la Lectura.

Es posible, entonces, que la esencia de la Historia de la Lectura consista en operar dentro de esta ambivalencia, en un intento por controlar racionalmente un ámbito tan evasivo y escurridizo como es el intento de descifrar el acto mismo de leer. La particularidad que subyace en el lector como una geografía de lo ambiguo, esto es, aquello que excede el caso específico y se multiplica en la proliferación innumerable de los símbolos, es una pauta que mora y perdura en lectores epocales.

En cierto sentido, estamos ante una materia que pugna por visibilizar un aspecto que tal vez sea imposible de desplegar; es decir, ¿cómo impacta y qué cambios produce en los individuos (y en los procesos históricos) la lectura? Hay en esto un verosímil que linda con la imposibilidad. 
Así, la Historia de la Lectura se transforma en un acontecer que requiere para su implementación de la capacidad creativa del historiador. Esta disciplina, entonces, al ceñir y ampliar dialécticamente sus resignificaciones, puede definirse como una modalidad de abordar los documentos. Presenta, a su modo, una alteración en la esfera documental a través de modelos cualitativos e interpretativos.

La Historia de la Lectura, por lo tanto, desde punto de vista lógico, se manifiesta como una imposibilidad pero no por ello incapaz de desarrollar espacios de verosimilitud (Chartier 1999; Darnton 1993). Las representaciones y las respuestas de los lectores pueden ser bengalas arrojadas a espacios siderales ignotos. Lo que acontece en el lector y sus mudanzas, luego de la mediación de la cultura escrita, resultan, en muchos casos, suposiciones o acercamientos preliminares. La Historia de la Lectura, en este acercamiento, emerge como un discurso conjetural. A pesar de todos estos asedios permanece inescrutable, sin un abordaje definitivo, con un culto fecundo por todo aquello que no sea un dogma. Carece de principios rectores y su esencia final es como la vida misma: un misterio encriptado en distintos devenires.

\section{Dos}

Ahora bien, ¿cuáles pueden ser las otras maneras de leer la Historia de la Lectura? Porque inequívocamente la Historia de la Lectura ya posee un relato textual formal establecido y una regulación terminológica de cómo se debe escribir acerca de esta asignatura. Esto es: posee una ortodoxia discursiva y retórica (Foucault: 2003); su propia poética aceptada por todos.

Solo la creación de un ámbito lingüístico distinto y autosuficiente está en condiciones de generar otro universo simbólico para explicar el fenómeno de la lectura; nos referimos a la presencia de un impulso con un nuevo recorte del lenguaje, que tienda a inaugurar una fuerza simbólica con la suficiente capacidad para explicar de otro modo el destino último (o siempre penúltimo) de ese acontecimiento inenarrable que es el leer y su dispositivo histórico.

La Historia de la Lectura no puede agotarse en la repetición de sus prácticas ni en los anhelos de sus imágenes. Para superarse y avanzar en una novedosa "meta-representación”, debe intentar fundar una Historia de la Lectura fuera de las convicciones actuales que de ella tenemos. Solo en estas condiciones se puede esperar un avance en sus investigaciones y tendencias futuras. En cierta manera, hay que permanecer ajeno al discurso establecido para fomentar la alteridad del discurso.

Ante la pregunta que establece los “cómos y los porqué” se lee, es posible también interrogarse sobre otras articulaciones de la lectura en los lectores (Darnton: 1993). Un tema de especial interés se centra en el mundo de los conceptos. En este marco que brinda la conceptuación de la Filosofía, es válido, en el campo especulativo, la interrogación sobre los cambios y mutaciones que producen los textos leídos en los conceptos de los lectores. Estos últimos, exiliados de los presupuestos del lenguaje, provocan, por su propio vértigo, reformulaciones de la realidad en aquellos que leen. Más allá de la importancia de meditar sobre las emociones y sensibilidades que ocasionan los textos, existe un campo desconocido por los historiadores de la lectura: el paisaje y la topografía, constantemente cambiante y múltiple, de los conceptos que crean las palabras al ser leídas.

De esta forma, los lectores se convierten en personajes conceptuales, con la capacidad para intervenir "en la propia creación de sus conceptos” (Deleuze y Guattari 1993: 65). Nuevamente se esboza una dinámica de compleja delimitación: ¿cómo puede desembarcar la Historia de la Lectura en el epicentro de las vívidas conceptuaciones lectoras? Una pregunta que implica un desafío o, tal vez, el artificio de la especulación para establecer las bases de una Filosofía de la Historia de los lectores.

Sin embargo, en la constelación de la cultura escrita, cuya finalidad es satisfacer un deseo solapado mediante la lectura, emerge la contundencia del libro en sus contingencias materiales. El libro, por lo tanto, se presenta, en su corporeidad, como un formato de evolución tecnológica. Su arquitectura (y su significado lingüístico) está condicionado por la tecnología libraria. 
Esta condición de "aparatosidad sobrenatural" del libro establece un entramado vinculante entre la lectura y las formas tecnológicas de leer. Los lectores se modifican con cada reforma e intervención del "cuerpo escrito”, pero no solo porque esos cambios corpóreos reagrupan en forma diferente a sus prácticas de acceso a las palabras sino, además, porque la tecnología de cada época hace a su libro como un logotipo material y un dispositivo de lectura evidentemente técnico.

La Historia de la Lectura, pues, puede leerse en la clave de su escenificación tecnológica: el scriptorium medieval donde se preparaba el códice de pergamino, la habilidad artesanal-metalúrgica de Gutenberg para crear los tipos móviles, el juego material e inmaterial del plasma en el libro electrónico. En el contexto presente, esta disciplina debe intentar responder a nuevas cuestiones que, acaso, no tengan respuesta: por ejemplo, ¿cómo modifican los conceptos de los lectores las nuevas y sucesivas tecnologías librarias ahora inmateriales?

Por otra parte, todo aquello que los historiadores de la lectura procuran poner en evidencia bajo un orden textual, constituye el universo de probabilidades eventuales, indeterminadas e imprevisibles en que deviene lo azaroso de la lectura.

Por lo tanto, en este itinerario de incertidumbres corales, se plantean nuevas interrogantes: ¿qué rol cumple lo caótico en las historias íntimas y personales de los lectores?, ¿la imprevisibilidad de las representaciones de lectura no serían, en definitiva, “respuestas ordenadas” y, por ende, un intento regulatorio del azar?, ¿el relato que establece el acontecimiento-lector es pura indeterminación o posee aspectos contingentes?

El temario a responder no es susceptible, por lo menos en el estado actual de esta disciplina, de respuestas convincentes. La Nueva Historia Cultural se gestó a partir de esta crisis científica del determinismo (Hunt: 1989). Cuando Lynn White (1968) planteó, a mediados del siglo XX, cuáles eran los cánones cambiantes de nuestra cultura, no hizo más que visibilizar esta situación al establecer, entre otras mutaciones, que la humanidad ha pasado del canon de la lógica y el lenguaje al canon de los símbolos y que, al mismo tiempo, migró del canon de la jerarquía de valores hacia el canon indeterminado del espectro de valores. La Historia de la lectura, con su multiplicidad de actores, sus crisis de autoría, sus generaciones materiales, sus complejas relaciones entre el significante y significado, sus tensiones discursivas establecidas y sus eventualidades interpretativas, responde a estas pautas paradigmáticas.

Resolver este fenómeno, o al menos articular su presencia, podría poner en escena a nuevos participantes inesperados, a saber: los fundamentos de una epistemología de los lectores.

Otro de los tópicos que posee su correlato con la posibilidad subyacente de un episteme en torno a los lectores, se relaciona con las tipologías de la lectura. Aunque las representaciones se transforman constantemente ante las diversas materialidades del libro, es posible establecer ciertos tipos de prácticas dentro y fuera del tiempo. ¿Existe, pues, un repertorio de lecturas infinito? $\mathrm{O}$, por el contrario, ¿la aparatosidad técnica del libro permite un conjunto de apropiaciones y excluye a otras?

Este conflicto no es vacuo ni insustancial. Porque se está dirimiendo la facultad de sistematizar ciertos usos de la cultura escrita. Muchos autores, en forma explícita o indirecta, comentan sobre el criterio de veracidad taxonómico. Así, se manifiestan los modos de leer de la intimidad o del retiro individual frente a los gregarios y sociales, las lecturas de la esfera católica y la protestante, los vínculos con la cultura impresa en las ciudades y su diferenciación en el ámbito rural, la circulación de las obras según los estudios de género, el libro y su distribución comercial como bien de consumo entre los sectores de elite y los desclasados, etcétera.

Cuando se intenta establecer el mapa clasificatorio de lecturas, se corre el riesgo de observar al lector en la autocomplacencia de cotejar su ornamento, ya vacío de contenido y transformarlo en una mercancía (Kracauer: 2008). Los criterios tipológicos, en las dimensiones lectoras, deben señalar que dichas sistematizaciones solo recuperan su pleno sentido si poseen una vocación asistemática. La Historia de la Lectura emerge como un verdadero paisaje de la cultura escrita, cuando manifiesta las complejas sinuosidades de esta latente imbricación 
entre el lector y sus tipologías fuera de toda clasificación.

El papel de la tan mentada ambigüedad de las dimensiones lectoras vuelve hacia nosotros en un cuasi eterno ritornello. Sin estos juegos de repetición y reconversión, donde lo metafórico, el tiempo, el mito, el pasado y el lenguaje reconfiguran al lector en otras articulaciones, no existiría una disciplina como la Historia de la Lectura.

La puesta en escena final del impulso de "narrar el leer” en el tiempo, acaso culminaría con una Metafísica de la lectura; esto es, con una sucesión de preguntas sobre su ontología, axiología y fenomenología, sobre sus condiciones de ser y sus finalidades.

"Si el lenguaje disfraza al pensamiento" (Wittgenstein: 2003), la Historia de la Lectura disfraza a los lectores. La totalidad de los hechos factibles de ser leídos tienden, como en un tratado de lógica, a resolverse en una reducción infinita al absurdo. Todas las dimensiones -reales, irreales, naturales, artificiales- son propicias a la lectura. El lector es, pues, la lectura, y todas las historias se resuelven mediante una Historia de la Lectura. Cada nuevo lector resulta un operador quirúrgico del texto final (Blanchot 1979: 272-273).

Sin embargo, hay otros espacios que no han sido aún abordados por los historiadores de estos operadores textuales: nos referimos al papel que pueden desempeñar la imaginación y la fantasía en la Historia de la Lectura. Como se ha señalado, los estados de tensión y los escenarios de disputas circunscriben a todas las vertientes que convergen en esta disciplina. Por esto último, y tal vez forzando otro espacio de heterodoxia, la Historia de la Lectura debería debatir sobre cómo y en qué condiciones se despliega lo imaginario y lo fantasioso en el mundo de los lectores. A la Historia de la Lectura, con frecuencia, se le escapan estos paisajes de lo maravilloso que, inequívocamente, están fuera del registro histórico, pero que son sustancialmente fértiles en las imágenes de los lectores.

¿Es posible rastrear a través del método indiciario los ámbitos de la imaginación y la fantasía? ¿Estamos ante un límite insuperable y que no incumbe a la Historia? La imaginación es una forma libre de acceder al conocimiento y los lectores están consustanciados, a través de su mediación, con los hechos dados. El punto de inflexión se centra en un aspecto nuclear: ¿cómo puede abarcar la Historia de la Lectura una historia de la imaginación lectora?

Además, tal como lo ha manifestado Johan Huizinga (1968), el juego es un fenómeno cultural. No deberíamos dejar a un lado lo lúdico en la lectura (sería un pecado de elite académica), pues la capacidad de jugar es otro acontecimiento humano que se desarrolla bajo el signo de la representación. La Historia de la Lectura comparte estos dos elementos inherentes al juego: lo cultural y la facultad de su representación. No es posible, pues, estudiar a los lectores sin invocar a la imaginación lúdica, es decir, a aquello que se inserta como una cuña en las zonas marginales de lo estrictamente racional. Porque, en definitiva, la Historia de la Lectura no puede estar ajena a la felicidad y a la libertad anárquica con que "operan” sus lectores.

A lo largo de esta exposición se han esbozado, con el objetivo manifiesto de motivar una instancia de discusión, los tropos heterodoxos de la Historia de la Lectura. Tópicos abiertos, provisionales, de inestabilidad creciente y, como la mayoría de los destinos teóricos, fugaces. Pero sin duda este simulacro posee su validez: el intento de pensar el relato histórico de esta disciplina desde otras constelaciones argumentativas. Reflexionar con los lectores a partir de los propios lectores trasplantados en el lugar de los historiadores y no, en forma rigurosa, desde estos últimos.

El título del presente ensayo proviene de una novela de Truman Capote (1976). El préstamo no es arbitrario ni accidental. Su enunciación reproduce el laberinto en el cual se interna la Historia de la Lectura de cara al futuro y, en el vórtice de esa prospección, clama por la necesidad de explorar esta materia desde otras voces y otros ámbitos. 


\section{BIBLIOGRAFÍA}

Blanchot, Maurice (1979). El libro que vendrá, Caracas, Monte Ávila Editores.

Buckland, Michael Keeble (1997). "What is a "document?”, Journal of the American Society for Information Science, 48(9), pp. 804-809.

Capote, Truman (1976) [1948]. Otras voces, otros ámbitos, Buenos Aires, Sudamericana.

Chartier, Roger (1993). “¿Qué es un autor?”, en Libros, lecturas y lectores en la Edad Moderna, Madrid, Alianza, pp. 58-89.

Chartier, Roger (1999). El mundo como representación. Historia cultural, entre práctica y representación, Barcelona, Gedisa.

Darnton, Robert (1993). “Historia de la Lectura”, en Peter Burke (Ed.). Formas de hacer Historia, Madrid, Alianza, pp. 177-208.

Deleuze, Gilles y Félix Guattari (1993). ¿Qué es la filosofía?, Barcelona, Anagrama.

Foucault, Michel (1999) [1969]. “¿Qué es un autor?” Recuperado de http//www.saber.ula.ve/bitstream/123456789/15927/1/davila-autor.pdf .

Foucault, Michel (2003) [1971]. El orden del discurso, México, Octaedro.

Frisby, David (1992). Fragmentos de la modernidad, teorías de la modernidad en la obra de Simmel, Kracauer y Benjamin, Madrid, Visor.

Geertz, Clifford (1990). La interpretación de las culturas, Barcelona, Gedisa.

Ginzburg, Carlo (1999). El queso y los gusanos, Barcelona, Muchnik.

Ginzburg, Carlo (2004). Tentativas, Rosario, Prohistoria ediciones.

Ginzburg, Carlo (2008). “Indicios, raíces de un paradigma de inferencias indiciales”, en Mitos, emblemas, indicios, Barcelona, Gedisa, pp. 185-239.

Ginzburg, Carlo (2010). El hilo y las huellas, lo verdadero, lo falso, lo ficticio, Buenos Aires, Fondo de Cultura Económica de Argentina.

Heidegger, Martin (2003). Arte y poesía, México, Octaedro.

Huizinga, Johan (1968). Homo ludens, Buenos Aires, Emecé.

Hunt, Lynn (Ed.) (1989). The New Cultural History, Berkeley, University of California Press.

Kracauer, Siegfried (2008). "El ornamento de la masa”, en La fotografía y otros ensayos. El ornamento de la masa 1, Barcelona, Gedisa, pp. 51-78.

White, Lynn (1968). Fronteras del conocimiento en el estudio del hombre, Buenos Aires, Eudeba, pp. 305-320.

Wittgenstein, Ludwig (2003). Tractatus logico-philosophicus, Madrid, Alianza. 